1. Doutora pela Universidade de Paris IV - Sorbonne, mestra pela COPPE-

-UFRJ, arquiteta e urbanista pela FAU-USP, professora do Departamento de Arquitetura e Urbanismo e da Pós-Graduação em Geografia da Universidade Federal de Santa Catarina, coordenadora do Núcleo Cidadhis-CNPq-UFSC. Bolsista da Capes, Pós-Doutorado na Universidade de La Rochelle, France

e-mails: afeche@arq.ufsc.br e pimenta.margareth@gmail.com.

DOI: 10.5752/P.2316-1752.2015v22n31p8 


\title{
PAISAGENS CULTURAIS: FRAGILIDADES DE PRESENÇAS IMPRESCINDÍVEIS
}

\author{
CULTURAL LANDSCAPES: FRAGILITIES OFTHE \\ INDISPENSABLES PRESENCES
}

PAISAJES CULTURALES: DEBILIDADES DE PRESENCIAS

IMPRESCINDIBLES

Margareth de Castro Afeche Pimenta ${ }^{1}$

\section{Resumo}

As Paisagens Culturais, introduzidas recentemente no Brasil, devem suscitar amplas coadjuvações de ajustamento. Visando a proteger também os grupos tradicionais inseridos em seu ambiente, significam um desafio diante das tendências econômicas hegemônicas. Daí decorre sua importância, mas também sua vulnerabilidade. A deriva desse conceito poderia obstaculizar a efetividade das políticas públicas nas diversas escalas territoriais, contrariando sua potencialidade de valorização das práticas socioculturais espacializadas, da memória histórica e da identidade dos lugares.

Palavras-chave: Paisagens culturais. Políticas patrimoniais. Cultura. Memória. Lugar.

\begin{abstract}
The politics of Cultural Landscapes, introduced recently in Brazil, should raise large contributions of adjustment. Seeking to protect the traditional groups in their environment, they mean a challenge to hegemonic tendencies. From their importance stems their own vulnerability. The drift of this concept could mean a loosening of the State effective surveillance in the various territorial scales, despite its potential for valuing the sociocultural practices, historical memory and identity of the places.
\end{abstract}

Keywords: Cultural landscapes. Heritage policies. Culture. Memory. Place.

\begin{abstract}
Resumen
Los Paisajes Culturales, introducidos recientemente en Brasil, deben dar lugar a extensas colaboraciones de ajuste. Con el fin de proteger a los grupos tradicionales insertados en su entorno, significan un desafío a las tendencias económicas hegemónicas. Desde aquí resulta su importancia, pero también su vulnerabilidad. La deriva de este concepto podría obstaculizar la eficacia de las políticas públicas, contrariamente a su potencialidad de valoración de las prácticas socioculturales espacializadas, la memoria histórica y la identidad de los lugares.
\end{abstract}

Palabras claves: Paisajes culturales. Políticas de patrimonio. Cultura. Memoria. Lugar. 


\section{A Paisagem Cultural: um contexto adverso}

São tantas e tão variadas as paisagens! Em algumas ainda permanecem os grupos tradicionais com suas práticas criativas e seu domínio de técnicas que condizem com as especificidades ambientais dos lugares. Essa diversidade cenográfica e esses saberes são o objeto de atenção das Paisagens Culturais, programa instituído pela UNESCO em 1972, visando a preservar, ao mesmo tempo, os lugares, os ambientes e suas culturas. A instauração da chancela da Paisagem Cultural no Brasil constitui, portanto, um avanço importante em termos de valorização da relação entre as expressões culturais dos diferentes grupos e o meio onde vivem, criando, assim, a possibilidade de se romper a dicotomia histórica na preservação de bens materiais e imateriais, pensando-os de forma integrada e interativa. Enquanto a preocupação com a proteção da paisagem já se faz presente na Europa do Pós-Guerra, por aqui a insistência no foco do objeto isolado resulta nos atuais cenários urbanos, principalmente nas grandes e médias cidades brasileiras. Quase não podem ser percebidos, claramente, os poucos imóveis isolados ou alguns conjuntos patrimoniais que ainda permanecem. Somente as cidades históricas que não sofreram com pressões imobiliárias significativas puderam ainda manter seu conjunto patrimonial, muitas vezes destituído das populações originais.

Apesar de o Brasil ter elaborado, de forma relativamente precoce (1937), a preocupação com os monumentos naturais, os sítios e as paisagens, os resultados efetivos foram relativamente fracos, se for considerada a enorme e pouco criteriosa alteração efetuada no ambiente natural ou construído. As pequenas propriedades e suas técnicas tradicionais foram grandemente substituídas, um pouco em toda parte, por grandes monoculturas exportadoras (PETRAS, 2013), empregando técnicas cada vez mais homogeneizantes e indiferentes ao ambiente em que se inseriam. As características dos sítios foram colocadas em segundo plano também nas expansões das cidades brasileiras. Rios, colinas, vegetação, horizontes, cultivos, entre outros, desaparecem da percepção urbana. O mesmo ocorre com as conformações dos conjuntos históricos, elaborados no decorrer dos diferentes períodos de evolução urbana. Permanecem poucos exemplares em meio a um enorme processo de substituição e de renovação, em geral incentivado pelos próprios planos diretores. Poder-se-ia descrever, grosso modo, nossas cidades como uma alta e densa massa edificada, que faz desaparecer tanto as características naturais dos sítios quanto dos imóveis patrimoniais, de forma efetiva ou apenas em termos de visualização. Perdeu-se o sentimento de paisagem, aquilo que vem ao "espírito", que se espera ver, e que se manifesta como representação, como composição material da apropriação da natureza pelo trabalho humano, que se percebe pelo olhar (BRUNON, 2009). Esvaneceu-se a evocação do passado e da história que as paisagens podem contar sobre os lugares. Se tivesse havido um crescimento urbano compatível com as heranças históricas, além das formas mais ou menos estáticas, fragmentadas pelo rápido circular automobilístico, perceber-se-iam, também, os movimentos das pessoas, dos ventos, os ruídos, os cheiros. Poder-se-iam 
observar, se ainda lá estivessem, o contorno dos morros, os vales dos rios, tipos vegetais diversos com suas floradas, as construções, os caminhos, as vias, e tudo ali acontecendo, a vida presente nessas formas que foram historicamente elaboradas. No campo, ainda se teria, também, em algumas áreas, uma paisagem matizada, respeitosa dos saberes, das habilidades e dos tempos da natureza.

Mas não foi assim que aconteceu. Apesar da precocidade da proteção patrimonial brasileira, com suas primeiras medidas elaboradas em 1937 (BRASIL, 1937), a duradoura persistência na seleção do imóvel isolado, primeiramente restrita aos monumentos, teve grandes implicações urbanas e sociais. Quando as manifestações culturais passam a ser inseridas nas políticas de preservação, mantém-se a separação entre bens materiais e imateriais, o que também ocorre em nível internacional, mas em muitas outras partes do mundo já prevalece a proteção de sítios e de grandes perímetros urbanos, valorizando, então, as paisagens rurais e urbanas.

Ainda restam hoje, no Brasil, conjuntos importantes a serem protegidos que têm grande expressividade em relação às nossas heranças culturais, mas o tempo conspira contra sua valorização. Se o patrimônio "ameaçado" se constitui numa preocupação explícita da UNESCO em termos mundiais, constando, inclusive, como um dos itens específicos de sua política patrimonial, aqui a questão adquire altos níveis de alerta. Tanto os locais de interesse patrimonial foram, muitas vezes, desprovidos de vida (JEUDY, 2005) quanto as manifestações culturais encontram-se ameaçadas pela disputa gananciosa de espaços cada vez mais rentáveis. A paisagem cultural, como categoria conceitual, aparece como possibilidade, se houver desejo político, de valorizar formas tradicionais de vida que dependem da preservação ambiental. Poderia significar uma ruptura no sentido de uma conciliação entre o homem e seu meio, produzindo espaços mais condizentes com a criatividade e a troca social, menos restritos à condição exclusiva de sua mercantilidade.

Devido às características atuais de incentivos prioritários a processos de concentração econômica, às monoculturas exportadoras e à liberalização crescente da proteção ambiental, as políticas de proteção associativa entre práticas sociais e ambiente precisam ser colocadas em primeiro plano, no sentido de preservar a rica diversidade natural e cultural que caracteriza nosso território nacional. Interessante observar que a categoria de paisagem cultural não se encontra relacionada, claramente, entre os elementos de preservação que são apresentados na página do IPHAN (Instituto do Patrimônio Histórico e Artístico Nacional) (portal.jphan.gov.br), da qual constam patrimônio material, imaterial, mundial, educação patrimonial, PAC das cidades históricas. Talvez isso reflita a subalternidade de sua importância em relação aos outros itens ou sintoma das dificuldades que atravessam atualmente as políticas culturais. Deve-se, no entanto, reconhecer que, apesar de ter sido inserida tardiamente no Brasil, 17 anos após sua aprovação internacional, ela já apresenta alguns importantes exemplares patrimoniais selecionados e chancelados. Se 
existem divergências de olhares ou de prioridades, cabe aqui ressaltar a importância do que hoje se constitui em objeto primordial da preocupação mundial: a relação entre o homem e a natureza ou entre a sociedade e seu meio.

As diferentes interpretações do conceito de paisagem cultural, muitas vezes, o colocam à deriva. Dessa forma errante, podem se perder as possibilidades de uma atuação mais precisa e mais incisiva. Faz-se necessário, portanto, resgatar o sentido da política da paisagem, porque dela depende a possibilidade de construção de um novo patamar de qualidade do espaço construído e de vida. Sem deixar de considerar o papel ainda desigual que representa como política de preservação, trata-se também de observar como o conceito de paisagem cultural, elaborado em nível mundial, foi introduzido no Brasil. Toma-se muitas vezes por coincidente o que, na verdade, apresenta diferenças significativas, que acabam por incidir em consequências díspares. Num debate que apenas se inicia, as diversas contribuições podem ajudar no ajustamento dos termos, o que se constitui numa das intenções aqui presentes. Sem se tratar de preciosismos acadêmicos, a elaboração conceitual pode permitir uma clareza na aplicação de recursos e de políticas que trarão resultados em curto, médio e longo prazos. Se a visão estratégica, apesar de necessária, tornou-se démodé no Brasil, ela é a única que pode permitir a ruptura nos rumos agressivos que conformam muitos de nossos espaços: desnaturalizados, ambientalmente destruídos, socialmente desapropriados e, em geral, precariamente desenhados, apesar de toda a criatividade popular e de toda capacitação técnica e, ou, artística que o País dispõe. A paisagem tem, também, o potencial de fazer dialogar várias áreas culturais em direção à construção de projetos diversos. Para isso, ela precisa ser colocada no centro do debate e deixar transparecer a riqueza das diversas contribuições. Aqui começa esta tarefa: pensar as políticas e o conceito de paisagem cultural, e as possibilidades que poderiam trazer em termos de condições de vida nos espaços elaborados pelos diferentes grupos culturais e sociais.

\section{Primórdios e evolução de uma ideia instigante}

Em 1962, a Conferência-Geral da UNESCO, na sua 12. a sessão, já recomendava a "salvaguarda da beleza e da característica das paisagens e dos sítios de preservação e, desde que seja possível, a restituição dos aspectos das paisagens e dos sítios, naturais, rurais ou urbanos, que sejam devidos à natureza ou à obra do homem". Uma definição tão ampla necessitava de complementação que atribuísse aos lugares escolhidos características peculiares, ou seja, que apresentassem "um interesse cultural ou estético", ou que constituíssem "meios naturais característicos" (UNESCO, 1962, p. 141). Essa preocupação relativamente precoce de consideração à proteção das paisagens já encontrava eco em alguns países europeus que elaboravam seus planos diretores do Pós-Guerra, nos quais se inseriam os perímetros de preservação e os conjuntos históricos, mas também as relações entre paisagens natural e cons- 
truída (ATELIER PARISIEN D'URBANISME, 1980; PIMENTA, 2010). O olhar em relação ao monumento isolado se impunha, no entanto, em diferentes países, pela influência dos ideais modernistas (BERMAN, 1986), mas já era contestado grandemente no Velho Mundo, que reagiu aos projetos renovadores, defendendo suas heranças históricas (HUET, 1987).

Dez anos mais tarde, a Conferência Geral da UNESCO, na sua 17. ${ }^{\text {s }}$ sessão (1972), reelabora os termos patrimoniais, classificando os monumentos, os conjuntos e os locais de interesse. Nos dois primeiros casos, pode-se considerar a tônica sendo atribuída ao objeto, mesmo que este seja composto por várias unidades. O aspecto da proteção paisagística seria dado pelos locais de interesse que poderiam ser "obras do homem, ou obras conjugadas do homem e da natureza, e as zonas, incluindo os locais de interesse arqueológico, com um valor universal excepcional do ponto de vista histórico, estético, etnológico ou antropológico." Reconhece a necessidade de preservação de sítios naturais, classificados como "locais de interesse naturais ou zonas naturais estritamente delimitadas", desde que apresentassem "valor universal excepcional do ponto de vista da ciência, conservação ou beleza natural" (UNESCO, 1972, p. 3).

Não se pode esquecer que os movimentos de proteção da natureza já se afirmavam nesse período. Eles começaram de forma pontual já no início do século XX, mas avançaram lentamente. Em 1902, realizou-se em Paris, com a participação de nove países europeus, a convenção internacional de proteção de espécies selvagens que, longe de se restringir ao tema, preconizou "a proteção absoluta de pássaros úteis à agricultura" (CROQUET; CROQUET, 2006). Em 1909, surgiram as primeiras iniciativas protecionistas: foram criados os parques naturais na Suécia. O Primeiro Congresso Internacional de Proteção da Natureza realizou-se em 1923 (Paris) e, em 1933, houve a convenção relativa à conservação da fauna e da flora em Londres, que abordou, pela primeira vez, a questão das espécies em extinção, reservas naturais e parques nacionais. Depois do interregno de duas guerras mundiais, seria a França a instituir as leis de zonas protegidas na década de 1960, com a lei sobre os parques naturais (CROQUET; CROQUET, 2006). Em 1967, a reserva zoológica e botânica de Camargue (França) já recebia o primeiro diploma emitido pelo Conselho Europeu pela contribuição no domínio da conservação da natureza (SOCIÉTÉ NATIONALE DE LA PROTECTION DE LA NATURE, 2015).

O grande passo no sentido de preservação natural seria dado em 1972, quando se realizou a Conferência da ONU em Estocolmo, reconhecendo ser de importância maior a proteção e a meIhoria do ambiente "que afeta o bem-estar das populações e o desenvolvimento econômico do mundo todo" (ORGANIZAÇÃO DAS NAÇÕES UNIDAS, 1972, p. 1). Paralelamente, mas com certa defasagem, desenvolveram-se as medidas de proteção patrimonial, que se deixam impregnar pelos ideais ambientalistas. A Carta de Nairóbi, de 1976, ampliou a ideia de "locais de interesse" e de "sítios de proteção natural", elaborada em 1972, incluindo toda instalação humana, em meio urbano como rural, que tenha valor patrimonial. Entendeu por "conjunto histórico

Cadernos de Arquitetura e Ubanismono, v.22, п.31, 2" sem. 2015 
ou tradicional" todo agrupamento de construções e espaços, aí incluídos os sítios arqueológicos e paleontológicos, constituindo um estabelecimento humano em meio urbano como rural, aqueles em que "a coesão e o valor são reconhecidos do ponto de vista arqueológico, arquitetônico, histórico, pré-histórico, estético ou sociocultural." Destacou, entre eles, "os sítios pré-históricos, os bairros antigos, as vilas e aldeias, assim como conjuntos monumentais homogêneos, devendo ser, estes últimos, preservados em sua integralidade" (UNESCO, 1976, p. 22). Entre suas definições principais, apresentou o "ambiente" dos conjuntos históricos ou tradicionais, ou seja, o contexto natural ou construído que afeta a percepção estática ou dinâmica desses conjuntos que se relacionam de maneira imediata no espaço ou por elos sociais, econômicos ou culturais. A ideia de totalidade já aparecia claramente, quando propôs que os conjuntos históricos ou tradicionais e seu ambiente deveriam, portanto, ser preservados em sua integralidade como "um todo coerente, cujo equilíbrio e caráter específico dependem da síntese de elementos que o compõem", o que incluiria tanto as atividades humanas como os edifícios, a estrutura espacial e as zonas ambientais. E para dar mais destaque, ainda ressaltou que todos os "elementos válidos, aí compreendidas as atividades humanas, mesmo as mais modestas, têm, em relação ao conjunto, uma significação que precisa ser respeitada" (UNESCO, 1976, p. 22). Em 1976, já estava retratada, assim, a superação da restrição à monumentalidade como critério de preservação. Reconheceu-se e valorizou-se a cultura produzida pelas populações em geral, com suas pequenas atividades, seus saberes e sua criatividade.

A consciência e os protestos ambientais não pararam de crescer, sintonizados com o agravamento das condições de deterioração física e humana, impostas pelo modo de produção capitalista, principalmente depois da segunda metade do século XX. Após a Conferência de Estocolmo, em 1972, eventos e documentos periódicos foram realizados, como a "Carta mundial pela natureza", elaborada em reunião da ONU de 1982, que abordou os ecossistemas (ORGANIZAÇÃO DAS NAÇÕES UNIDAS, 1982, p. 19). Ainda sem alcance jurídico, essa resolução influenciou a Conferência do Rio de Janeiro, em 1992, que elaborou, como preocupação central, o conceito de desenvolvimento sustentável. Segundo o documento aprovado, as proposições desse evento apoiavam-se em duas grandes preocupações, que seriam decorrentes da análise dos fatos que teriam sido testemunhados no intervalo daqueles 20 anos que separavam as duas conferências (1972 e 1992): "A deterioração do ambiente, principalmente em sua capacidade de manter a vida, e a interdependência cada vez mais manifesta entre o progresso econômico a longo prazo e a necessidade de proteção do ambiente" (ORGANIZAÇÃO DAS NAÇÕES UNIDAS, 1992).

Seria paralelamente, também em 1992, na Convenção do Patrimônio Mundial da UNESCO, elaborado o primeiro instrumento jurídico internacional para definir, reconhecer e proteger as paisagens culturais. Evoluiu, de forma significativa, em relação à concepção de proteção instituída pela Convenção de 1972, 
até então predominante, que tratava o espaço e a proteção patrimonial pelos seus componentes formais (monumentos, conjuntos e locais de interesse). Revalorizou os preceitos de Nairóbi (1976), mas atribuía significados mais específicos em termos de preservação ambiental.

Os avanços de 1976 são inegáveis, tanto em termos de definição da ideia de totalidade a ser preservada, quanto na valorização das atividades humanas, mesmo as mais modestas. No entanto, a paisagem cultural fecha ainda mais o foco sobre o trabalho humano e sua interação com a natureza. Daí advém grandes possibilidades de proteção efetiva de pequenas atividades tradicionais, ricas em termos culturais, mas incapazes de resistir, sem a proteção de políticas públicas, à lógica do processo de acumulação. A concentração econômica e a formação dos grandes grupos insistem em se apropriar, de forma cada vez mais ampliada, de todas as áreas, inserindo-as num circuito mercantil sempre atualizado (MARX, 1974). E daqui, talvez, se inicie, a partir de visões e de posições diferenciadas, a divergência das interpretações do conceito de paisagem cultural.

\section{A paisagem cultural: compreensões divergentes}

Em 1992, a paisagem cultural foi reconhecida como objeto da política de proteção patrimonial em nível mundial. A $16^{a}$ Sessão da Convenção do Patrimônio Mundial adotou as orientações para inscrição na Lista do Patrimônio Mundial. As paisagens culturais foram definidas, então, como "as obras combinadas da natureza e dos homens". Ela é testemunho, registro de diversas épocas que podem ser presenciadas no momento atual e que significam a forma de apropriação da natureza pelo homem, com suas técnicas e suas representações.

A paisagem cultural está diretamente interessada na preservação dos meios rurais, pois coloca o manuseio das terras no centro de suas atenções, reconhecendo a grande diversidade decorrente das características especificas do ambiente e dos grupos. Constata, portanto, que existe uma enorme variedade de "manifestações interativas entre homem e seu meio natural", que refletem, frequentemente, formas específicas de "utilização viável das terras, tomando em consideração as características e os limites do meio natural", assim como "uma relação espiritual específica com a natureza" (UNESCO,2008).

Essa incorporação do homem em relação ao meio em que vive coaduna-se com os interesses maiores de preservação do ambiente. Estabelece uma proteção dos elementos constituintes do espaço, mas incorpora também as técnicas empregadas e, sobretudo, a persistência das formas tradicionais de uso da terra, preocupando-se com a manutenção da diversidade biológica (UNESCO,2008). A postura incisiva da UNESCO é quase um resgate e uma tomada de posição diante dos riscos ambientais já detectados no mundo atual. Reconhece, então, que essas "formas tradicionais de utilização das terras mantêm a diversidade biológica de numerosas regiões do mundo", ou seja, que revalorizam as características físicas dos lugares e vivem em harmonia com a preservação 
ambiental. "A proteção das paisagens culturais tradicionais é, por consequência, útil para manutenção da diversidade biológica" (UNESCO, 1992). Desta feita, proteger as formas convencionais de manejo da terra significa, ao mesmo tempo, preservar tradições culturais e a biodiversidade. Em nenhum outro momento da história, o significado da preservação adquiriu uma dimensão tão ampla, tanto em termos espaciais quanto temporais. O lugar passa a testemunhar a engenhosidade humana, mas também faz parte de nossa memória (HALBWACHS, 1967) e de nossa identidade coletiva (JEUDY, 1990), assim como da possibilidade de construção de um mundo diversificado em termos culturais e ambientais.

A definição de paisagens culturais como as "obras conjugadas do homem e da natureza" centra o olhar nas maneiras de apropriação do ambiente e nos resultados do trabalho humano, assim como nas formas de representação dos diversos grupos sociais. Por isso valoriza as técnicas e o saber adquirido. A paisagem passa a ser compreendida como um produto de interface entre homem e natureza, "um processo de vai e vem entre sujeito e objeto" (BERTRAND, 1992, p. 316). O foco patrimonial desloca-se do objeto em si e preocupa-se com "a evolução da sociedade e dos estabelecimentos humanos ao longo dos tempos, sob a influência dos condicionamentos materiais e/ou das vantagens oferecidas pelo seu ambiente natural e das sucessivas forças sociais, econômicas e culturais, externas e internas" (UNESCO, 2012, p. 11).

No sentido de especificar melhor as orientações para propor a inserção de exemplares nas listagens dos bens a serem protegidos, as paisagens culturais foram subdivididas, posteriormente, em três categorias principais. A primeira e mais facilmente identificável é a paisagem desenhada e criada pelo homem, como os jardins e os parques. Podem, ou não, estar "associadas a edifícios religiosos ou outros edifícios e conjuntos monumentais" (UNESCO, 2008, p. 89).

A segunda categoria, apesar de mais detalhada, é mais difusa, porque pode ser confundida com as paisagens em geral. Trata-se de paisagens organicamente evoluídas, que foram criadas por um "imperativo inicial social, econômico, administrativo e/ ou religioso e desenvolveu a sua forma atual por associação e em resposta ao seu ambiente natural." Dificilmente se pode achar alguma paisagem que não se insira nessa caracterização. Pretende-se que sejam caracterizadas pelo "processo de evolução na sua forma e características componentes." Para isso, são subdivididas em duas subcategorias: 1. relíquia (ou fóssil), quando o processo evolutivo foi estancado em "algum momento no passado, quer de forma abrupta ou durante um período", mas ela ainda permanece em sua forma material; 2. paisagem contínua, quando "conserva um papel social ativo na sociedade contemporânea, intimamente associado ao modo de vida tradicional, e no qual o processo evolutivo ainda está em andamento" (UNESCO, 2008, p. 89). Nos dois casos, a ênfase está dada na relação entre o ambiente e as atividades humanas, a partir da utilização de formas tradicionais que, mesmo não sendo estáticas, constituem elas mesmas o foco da preservação, tendo desaparecido no passado ou estando ainda presentes. 
A última classificação refere-se à paisagem cultural associativa, que foi inserida sob a justificativa "da força de associação entre fenômenos religiosos, artísticos ou culturais do elemento natural", que prevalece, nesse caso, aos "traços culturais tangíveis que podem ser insignificantes ou mesmo inexistentes" (UNESCO, 2008, p. 90). Essas paisagens deveriam ser preservadas, porque são os lugares onde esses eventos se realizam, impregnando-lhes de significados culturais significativos.

As desorientações decorrentes da amplitude com que pode ser compreendida a paisagem cultural levam a UNESCO a estabelecer certas precisões, tendo em vista sua aplicabilidade em termos de políticas de preservação. Toda paisagem, por definição, é cultural, porque resultado do trabalho humano, refletindo o emprego das técnicas e a cultura de seu tempo. A paisagem poderia ser considerada "o conjunto de formas que, num dado momento, exprimem as heranças que representam as sucessivas relações localizadas entre homem e natureza" (SANTOS, 2006, p. 66). Para especificá-la como item de proteção, acrescentou-se a característica de "paisagem singular", definida como "resultado e a causa do desenvolvimento de valores culturais", na interação humana estabelecida com os sistemas naturais (MITCHELL; RÖSSLER; TRICAUD, 2011). Ainda assim, os equívocos são possíveis, e a UNESCO reconhece que "a mais facilmente identificável é a paisagem claramente definida, concebida e criada intencionalmente" (MITCHELL; RÖSSLER; TRICAUD, 2011), sendo as demais ainda objeto de maiores esclarecimentos.

As obras efetivamente protegidas pela UNESCO até o momento deixam, no entanto, a possibilidade de se afinar a análise dos critérios estabelecidos. Pode-se observar, na escolha dos 88 sítios selecionados pela UNESCO até 2015, uma grande variedade de paisagens decorrente da própria diversidade natural e cultural. Existem locais intencionalmente projetados (como parques, jardins, villas italianas, templos pagodes, etc.) e lugares sagrados (florestas, por exemplo) ou simbólicos, sítios arqueológicos. A particularidade na apropriação do ambiente também é destacada em sítios excepcionais, como áreas pantanosas no Canadá, associadas a vestígios de antigas vilas, "que testemunham um admirável esforço técnico multissecular de zona intertidal agrícola, numa situação marítima com coeficientes de marés excepcionais" (UNESCO, 2015). Inclui-se também uma combinação entre monumentos urbanísticos e arquitetônicos em sítios espetaculares, como os Vales do Reno, Vale da Loire, Vale do Danúbio. No entanto o que merece destaque é que a maior parte dos locais escolhidos se refere às formas históricas de interação com a natureza, a partir do emprego de técnicas tradicionais. Aos exemplos já citados sobrepõem-se as terras indígenas ou de populações tradicionais, cultura em terraços, minas, viticulturas, muitos sítios e culturas agrícolas diversos, pastagens.

A existência de formas tradicionais de vida ainda presentes, mesmo em processo de evolução, aproxima essa concepção da visão da antropologia cultural, fundada por Tylor, no final do século XIX. Em seu livro "Primitive culture" (1871), define cultura ou civilização, tomada "em seu amplo sentido etnográfi- 
co", como "todo complexo que inclui conhecimento, crença, arte, moral, lei, costume e quaisquer outras capacidades e hábitos adquiridos pelo homem como membro da sociedade" (TYLOR, 1920, p. 1). Cada um desses itens, no entanto, não comparece como realidade em si, pois os fatos sociais são interdependentes e aparecem relacionados. Existem, portanto, "sistemas complexos e solidários que, sem ser limitados a um organismo político determinado, são, portanto, localizáveis no tempo e no espaço" (MAUSS, 1913, p. 48). São essas características que dão, assim, especificidade aos lugares. São as características dos sítios, apropriados pela lapidação cultural dos grupos que ali vivem. O espaço deixado à imaginação não se encaixa na rigidez da geometria. "Ele é vivido. E ele é vivido, não em sua positividade, mas com todas as particularidades da imaginação" (BACHELARD, 1961, p. 27). Estabelece-se, portanto, um elo insubstituível entre grupo social e lugar, ali onde um cotidiano é "compartido entre as mais diversas pessoas, firmas e instituições" e se realiza a vida em comum (SANTOS, 2006, p. 218).

Se é possível que sejam retiradas algumas conclusões até o presente momento, estas seriam relativas à necessidade de se resguardar as populações locais e, por outro lado, de se elucidar quais as paisagens deveriam ser efetivamente preservadas. Se um dos dois fatores ficar indefinido ou sem limitação precisa, teme-se que o sentido mesmo da paisagem cultural se esvazie. Pode-se resvalar, facilmente, para a preservação imaterial ou material, definindo-se as técnicas a serem preservadas sem proteger as paisagens ou, por outro lado, chamando a atenção para locais de interesse, mas sem atentar para medidas efetivas de proteção dos pequenos grupos vulneráveis, que utilizam, ainda, técnicas e modos de produção tradicionais.

\section{A chancela brasileira de paisagem cultural}

Inspirada nas diretrizes internacionais, a Portaria $n^{\circ} 127$ do Instituto do Patrimônio Histórico e Artístico Nacional, de 30 de abril de 2009, estabelece, em seu artigo $1^{\circ}$, que a "Paisagem Cultural Brasileira é uma porção peculiar do território nacional, representativa do processo de interação do homem com o meio natural, à qual a vida e ciência humana imprimiram marcas ou atribuíram valores" (INSTITUTO DO PATRIMÔNIO HISTÓRICO E ARTÍSTICO NACIONAL, 2009). Em suas considerações iniciais, faz constar "que o Brasil é autor de documentos e signatário de cartas internacionais que reconhecem a paisagem cultural e seus elementos como patrimônio cultural e preconizam sua proteção" (destaque nosso). Apesar de se colocar como partícipe de um mesmo movimento mundial, o dispositivo jurídico utilizado no Brasil, a chancela, não constitui propriamente um instrumento de proteção, como preconiza a UNESCO quando trata da paisagem cultural. Quando define a finalidade dessa regulamentação, a proteção desse patrimônio não consta como uma das razões da homologação da chancela, mas objetiva "contribuir para a preservação do patrimônio cultural, complementando e integrando os instrumentos de promoção e proteção existentes, nos termos preconizados na 
A chancela significa um reconhecimento, ou seja, um "selo ou sinal gravado em metal, utilizado para ser aposto em certos documentos oficiais, com o fim de autenticá-los" (ÂMBITO JURÍDICO, 2008). Constitui-se numa rubrica, utiliza-se para "suprir assinatura em documentos ou pôr a marca da repartição" (MICHAELIS, 2015). Assim, o IPHAN reconhece certas paisagens culturais, mas pode, ou não, utilizar-se de mecanismos complementares que, estes sim, poderiam preservar o bem em questão. O próprio IPHAN reconhece, no entanto, "que os instrumentos legais vigentes que tratam do patrimônio cultural e natural, tomados individualmente, não contemplam integralmente o conjunto de fatores implícitos nas paisagens culturais" (INSTITUTO DO PATRIMÔNIO HISTÓRICO E ARTÍSTICO NACIONAL, 2009).

Entre as categorias apontadas pela UNESCO, somente as paisagens ativas, ou seja, aquelas que ainda mantêm a relação entre os grupos tradicionais e o ambiente não tinham ainda, em nível internacional ou nacional, nenhuma proteção patrimonial. As demais poderiam supor a proteção como bem material ou imaterial, como no caso das expressões culturais ou das representações simbólicas. Somente a relação ativa entre ambiente e grupo social tradicional depende totalmente do estatuto da paisagem cultural, como única forma de proteção. Daí resulta sua importância, mas também sua vulnerabilidade, porque são exatamente essas interações que estão ameaçadas pelos interesses econômicos hegemônicos. Aqui se faz necessária a atuação efetiva e contundente do Estado.

A chancela da Paisagem Cultural Brasileira implicaria "no estabelecimento de pacto que pode envolver o poder público, a sociedade civil e a iniciativa privada, visando à gestão compartilhada da porção do território nacional assim reconhecida" (INSTITUTO DO PATRIMÔNIO HISTÓRICO E ARTÍSTICO NACIONAL, 2009). Parte-se do pressuposto de que os segmentos implicados (Poder Público, a sociedade civil e a iniciativa privada) sejam equivalentes em termos de poder de decisão. Nada mais duvidoso. Existe uma desigualdade inerente que somente pode ser corrigida pela mediação de políticas públicas, contrariando a tendência à concentração econômica e à destruição das formas tradicionais. Numa situação em que essas áreas não estivessem sendo objeto de disputas, poder-se-ia, provavelmente, firmar acordos de proteção, sem muitos conflitos. Assim tem acontecido no Brasil. Mantiveram-se, até o momento, somente as áreas que ficaram fora da avidez das atividades econômicas (incluindo-se, entre elas, o setor turístico-imobiliário). Estão preservadas até o momento, o que não significa que estão definitivamente protegidas, porque o processo de expansão capitalista avança sempre em direção a novas aquisições territoriais. O capitalismo tem a tendência de se expandir indefinidamente, reorganizando áreas e setores considerados "atrasados", de forma a submetê-los às novas lógicas dos grupos econômicos, cada vez mais concentrados e concentradores de capitais (MARX, 1974). Aqui residem, ao mesmo tempo, os riscos e as grandes potencialidades das pai- 
sagens culturais. Como desafio à tendência homogeneizante, pode (e deve) promover a rica diversidade cultural e natural, no Brasil e no mundo.

O artigo $3^{\circ}$ da Portaria $n^{\circ} 127$ do IPHAN vem corroborar essas ansiedades, quando a chancela da Paisagem Cultural Brasileira considera que "o caráter dinâmico da cultura e da ação humana sobre as porções do território a que se aplica, convive com as transformações inerentes ao desenvolvimento econômico e social sustentáveis e valoriza a motivação responsável pela preservação do patrimônio" (INSTITUTO DO PATRIMÔNIO HISTÓRICO E ARTÍSTICO NACIONAL, 2009). Só que nem sempre é assim. Existe, realmente, uma relação estreita entre comunidades tradicionais e sustentabilidade, como assevera a UNESCO e, posteriormente, o IPHAN. Só que essas formas tradicionais se dissolvem ao mesmo tempo que as paisagens no Brasil, até porque o modelo adotado supõe a monocultura exportadora e as atividades extrativas, de forma quase hegemônica, ambas ameaçadoras em relação ao ambiente, mas sobretudo frente aos grupos sociais tradicionais, desqualificando-os e transformando-os, na melhor das hipóteses, em trabalhadores assalariados mal remunerados. Será que não seria necessário um sincronismo com outras medidas de caráter macroeconômico e de estímulo às pequenas atividades? Tais seriam os casos, por exemplo, das vilas pesqueiras e das pequenas comunidades rurais que têm práticas culturais tradicionais associadas ao ambiente em que vivem. São ricas culturalmente, mas frágeis do ponto de vista da competição econômica e, por isso, estão ameaçadas de extinção no curto prazo. São essas formas que foram objeto privilegiado da proteção patrimonial da UNESCO, quando se refere às paisagens culturais. Seria um enorme ganho se, no Brasil, elas também fizessem parte de uma atenção especial com medidas de proteção efetiva. Somente a defesa do interesse público (DUGUIT, 2004) pode conseguir se contrapor a forças econômicas poderosas, como fica demonstrado, historicamente, pelo Estado do bem-estar social nos países europeus, de onde saíram as medidas protecionistas mais efetivas em termos patrimoniais (ATELIER PARISIEN D'URBANISME, 1983).

Não se pode observar essa pretensa relação de harmonia entre ambiente e caráter dinâmico da cultura num país em que as mudanças são comandadas pelo estimulo à inserção de novas formas de produção cada vez mais rápidas, eficientes e padronizadas. A realidade da imposição de forças econômicas sobre frágeis produções artesanais e manufatureiras tem demonstrado que os conflitos de interesse se resolvem, no Brasil, com o aniquilamento de paisagens que poderiam ser consideradas culturais.

Resta a ponderação a ser feita entre dinamismo econômico e revitalização patrimonial, para que essa relação, instável e conflituosa, não venha em detrimento das heranças culturais, o que, em geral, tem sido constatado de forma recorrente. Fica-se numa linha tênue entre o risco de transformação total ou do esvaziamento das paisagens que são transformadas em cenários (JEUDY, 2005), com as populações tradicionais substituídas, o que é uma constante nas áreas turísticas atuais. 
Apontando nesse sentido, o IPHAN propõe-se ao desígnio arrojado de preservar "cenários de vida peculiares e dos tipos humanos do Brasil, associados a biomas, ecossistemas e regiões geomorfológicas específicas", o que constitui hoje tarefa primordial, relatando ainda as áreas passíveis de atenção, que seriam as mais vulneráveis atualmente, como o "Pantanal, a Amazônia, a Mata Atlântica, as zonas costeiras, as planícies ribeirinhas, os vales e montanhas, os planaltos, o sertão, o agreste, a caatinga, o cerrado". Até aqui, existe uma coincidência com as definições universais de associação entre práticas humanas e sua interação com o ambiente, o que não ocorre mais adiante quando insere "até mesmo a selva de pedra das grandes cidades" (DELPHIM, 2011, p. 17). Essas ampliações podem fazer resvalar a visibilidade das proposições por campos indefinidos, suscitando preocupações e podendo levar ao emprego indiscriminado do conceito de paisagem cultural, o que significaria a perda de sua eficiência como medida de proteção patrimonial. Não se pode esquecer ainda que os orçamentos são sempre limitados. As escolhas implicam em renúncias. Elas vêm sempre em detrimento de outras possibilidades. Se as "selvas de pedra" têm motu proprio, o mesmo não pode ser dito das paisagens tradicionais ainda preservadas. Estas são as mais vulneráveis, mas contém em si a riqueza da diversidade das formas de expressão, dos fazeres e da habilidade no trato ambiental. Políticas explicitamente diferenciadas poderiam orientar, mais claramente, as diversas instâncias que se ocupam da questão patrimonial. Entre riscos e possibilidades, resta ajustar os mecanismos de proteção, sem considerar somente os lugares onde os embates não se realizarão no presente imediato, porque ainda são incapazes de atrair amplos movimentos de renovação urbana ou rural.

\section{Paisagens culturais: inquietações e expectativas}

Os processos concomitantes entre conquistas ambientais e culturais foram certamente decisivos para a ampliação da escala de proteção patrimonial, mas também para a possibilidade de elaboração de políticas integradoras de preservação entre as manifestações culturais e o meio em que se inserem. Assim, as paisagens culturais têm um significado inusitado. Representam uma transformação qualitativa em termos de visão de preservação, sem se constituir somente numa ampliação das áreas a serem protegidas. Por se defrontar diretamente com as tendências do processo de acumulação capitalista, sua proteção precisa ser cuidadosamente elaborada.

O Brasil substitui a proposta da UNESCO de proteção das paisagens culturais pela chancela, como elemento complementar das políticas de preservação do patrimônio material e imaterial que já existem. A Convenção do Patrimônio Mundial, no entanto, considera ter instituído "o primeiro instrumento jurídico internacional a reconhecer e proteger as paisagens culturais", adotando "orientações para inscrevê-las na listagem de patrimônio mundial" (grifo nosso). As paisagens culturais, segundo a UNESCO, constituem-se em bens passíveis de constar de 
uma lista de bens protegidos, como qualquer outra categoria a ser preservada (UNESCO, 2008).

Mas as diferenças não param por aí. Tanto os conjuntos históricos ou tradicionais como o ambiente em que se inserem deveriam ser considerados "patrimônio universal insubstituível", e sua salvaguarda deveria ser "um dever dos governos e dos cidadãos" onde estão situados, no interesse de toda a comunidade internacional (UNESCO, 1976, p. 22). Presta, portanto, a devida atenção à necessidade de os poderes públicos serem responsáveis pela preservação patrimonial como um bem universal que não pode ser substituído ou resgatado. Tal é o caso dessas pequenas e vulneráveis estruturas, cujas populações tendem a ser deslocadas, deixando muitas vezes a paisagem sem suas ricas formas de expressão cultural.

Levando-se em conta o papel crescente atribuído às administrações locais, sobretudo com os pactos aqui propostos pelo IPHAN em termos de políticas patrimoniais, trata-se do encadeamento de um debate, que permita a permeabilidade na compreensão do significado e da importância da preservação das paisagens culturais. As ações municipais, na maior parte das regiões brasileiras, são desencorajantes. Se for possível se aprender com a história, o Brasil necessita mais de rupturas do que do enlaçamento de um processo que venha se desenvolvendo de forma a valorizar os patrimônios naturais e culturais. Num contexto ainda hoje desfavorável em termos de modelo de desenvolvimento, onde as forças econômicas estão cada vez mais liberalizadas, todos os alertas e precauções se fazem necessários, sobretudo se for considerada a extrema importância das paisagens como referencial estético e de identidade dos lugares (BACHELARD, 1961).

Dos processos intuitivos até os mais conceituais, pode-se afirmar, de forma mais ou menos segura, que existe uma relativa compreensão universalizada do que seja paisagem, em seu sentido amplo. Se as paisagens se constituem, cada uma delas, como "um conjunto heterogêneo de formas naturais e artificiais" (SANTOS, 1988, p. 65), nem todas merecem a tutela do Estado; algumas, no entanto, necessitam dela, de forma contundente. São aquelas marcadas "pelas técnicas materiais que a sociedade domina e moldada para responder às convicções religiosas, às paixões ideológicas e aos gostos estéticos dos grupos" (CLAVAL, 2007, p. 14). Elas representam um testemunho das formas culturais, como "um documento-chave para a compreensão das culturas, o único que, frequentemente, subsiste das sociedades do passado" (CLAVAL, 2007, p. 14). Sem elas se esvanece a evocação do passado e da história que as paisagens podem contar sobre os lugares, suas formas de vida e suas representações. Tratar-se-ia de se preservarem os ambientes de memória, evitando que o "sentimento de continuidade seja residual aos lugares" (NORA, 1984, p. XVII). Pelo menos alguns lugares ainda mantêm tal virtualidade, que faz coincidir especificidade e evocação sensível. Por isso suscita lembranças, permite devaneios (BACHELARD, 1961), o que os torna exclusivos, lembrando que o "memorável é aquilo que se pode sonhar a respeito do lugar" (CERTEAU, 1998, p. 190). 


\section{Referências}

ÂMBITO JURÍDICO. Enciclopédia jurídica. Rio Grande: Âmbito Jurídico, 2008. Disponível em: <http://www.ambitojuridico.com.br./site/>. Acesso em: 11 mar. 2015.

ATELIER PARISIEN D'URBANISME (APUR). La politique de protection du patrimoine architectural et urbain. Paris Projet, Paris, n. 23-24, p. 171-202, $1^{\circ}$ trim. 1983.

ATELIER PARISIEN D'URBANISME (APUR). Schema Directeur d'Aménagement et d'Urbanisme (SDAU) de la Ville de Paris. Paris-Projet, n. 19-20, 1980.

BACHELARD, Gaston. La Poétique de I'espace. Paris: Presses Universitaires de France, 1961.

BERMAN, Marshall. Tudo que é sólido desmancha no ar: a aventura a modernidade. São Paulo: Companhia das Letras, 1986.

BERTRAND, Georges. Le paysage: I'irruption du sensible dans les politiques d'environnement et d'aménagement. Treballs de la Societat Catalana de Geografia, n. 33-34, v. 7, 1992.

BRASIL. Decreto-Lei n. 25, de 30 de novembro de 1937. Organiza a proteção do patrimônio histórico e artístico nacional. Portal da Legislação, Brasília, Presidência da República. Disponível em: <http://www.planalto.gov.br/CCiVil_03/Decreto-Lei/Del0025.htm >. Acesso em: 21 out. 2011.

BRUNON, Hervé. Du paysage comme patrimoine immatériel. Cahiers Jean Hubert, Lyon, n. 3, p. 173-176, 9 set. 2009.

CERTEAU, Michel. A invenção do cotidiano. Petrópolis: Vozes, 1998.

CLAVAL, Paul. A geografia cultural. Tradução de Luís Fugazzola Pimenta e Margareth de C. Afeche Pimenta. Florianópolis: Editora da UFSC, 2007.

CROQUET, Virginie; CROQUET, Jean-Charles. Historique de la naissance du droit de la protection de la nature au niveau mondial. Le droit de la protection de la nature en France, out. 2006. Disponível em: <http://droitnature.free.fr/Shtml/NaissanceDroitEnvMonde.shtml>. Acesso em: 5 jan. 2015.

DELPHIM, Carlos Fernando de Moura. Reflexões sobre a chancela de paisagem cultural brasileira. Brasília: Iphan; Coordenação de Paisagem Cultural, 2011.

DUGUIT, León. Fundamentos do Direito. Florianópolis: Letras Contemporâneas, 2004

HALBWACHS, Maurice. La mémoire collective. Paris: Presses Universitaires de France, 1967.

HUET, Bernard. A cidade como espaço habitável: alternativas à Carta de Atenas. Revista AU-Arquitetura e Urbanismo, São Paulo, n. 9, p. 82-87, dez. 1986/jan. 1987.

INSTITUTO DO PATRIMÔNIO HISTÓRICO E ARTÍSTICO NACIONAL (IPHAN). Portaria $n^{\circ}$ 127, de 30 de abril de 2009, assinada por Luiz Fernando de Almeida (presidente). Diário Oficial da União, seção 1, n. ${ }^{\circ}$ 83, p. 17, terça-feira, 5 maio 2009. 
JEUDY, Henri-Pierre. Espelho das cidades. Rio de Janeiro: Casa da Palavra, 2005.

JEUDY, Henri-Pierre. Memórias do social. Rio de Janeiro: Forense Universitária, 1990.

MARX, Karl. O capital. México: Fondo de Cultura Económica, 1974.

MAUSS, Marcel. Note sur la notion de civilisation. L'Année Sociologique, n. 12, p. 46-50, 1913.

MICHAELIS. Dicionário. São Paulo: Melhoramentos, 2009. Disponível em: <http://michaelis.uol.com.br>. Acesso em: 11 mar. 2015.

MITCHELL, Nora; RÖSSLER, Mechtild;TRICAUD, Pierre-Marie (org.). Paysages culturels du patrimoine mondial: guide pratique de conservation et de gestion. Cahiers 26 du Patrimoine Mondial. Paris: UNESCO, 2011.

NORA, Pierre. Entre mémoire et histoire: problématique des lieux. In: NORA, Pierra (org.). Les lieux de mémoire. Paris: Galllimard, 1984, v. 1. (La République, p. VII-XLII).

ORGANIZAÇÃO DAS NAÇÕES UNIDAS (ONU). Déclaration de Rio sur l'environnement et le développement principes de gestion des forêts. In: CONFERÊNCIA DAS NAÇÕES UNIDAS SOBRE O MEIO AMBIENTE E O DESENVOLVIMENTO, Rio de Janeiro, 3-14 de junho de 1992. Organização das Nações Unidas. Genebra: UNESCO. Disponível em: <http://unesco.un.org/ french/events/rio92/rio-fp.htm>. Acesso em: 23 fev. 2015.

ORGANIZAÇÃO DAS NAÇÕES UNIDAS (ONU). Déclaration finale de la Conférence des Nations Unies sur l'Environnement, Stockholm, 5 au 16 juin 1972. Disponível em: http://www. unep.org/. Acesso em: 15 de fevereiro de 2015.

ORGANIZAÇÃO DAS NAÇÕES UNIDAS (ONU). Charte mondiale de la nature. In: Résolutions adoptées par l'Assemblee Générale au cours de saTrente-Septième Session, 1982, p. 19-21. Disponível em: <http://www.un.org/french/documents/ view_doc.asp? symbol=A/RES/37/7\&Lang=F>. Acesso em: 23 fev. 2015.

PETRAS, James. Brazil: extractive capitalism and the great leap backward. The James Petras Website, 2013. Disponível em: <http://petras.lahaine.org/?p=1945>. Acesso: 30 jul. 2013.

PIMENTA, M. de C. A. Planejamento urbano: partindo de um conceito de cidade e de sociedade. In: MARTINS, César, MARTINS, Solismar; SILVA, Susana (orgs.). Quintas urbanas: conversas sobre a cidade e o urbano. Rio Grande: FURG, 2010, p. 51-85.

SANTOS, Milton. A natureza do espaço: técnica e tempo, razão e emoção. São Paulo: Editora da Universidade de São Paulo, 2006.

SANTOS, Milton. Metamorfoses do espaço habitado. São Paulo: Hucitec, 1988.

SOCIÉTÉ NATIONALE DE LA PROTECTION DE LA NATURE (SNPN). De la société d'acclimatation à la société nationale de protection de la nature. Paris: Société Nationale de Pro- 
tection de la Nature. Disponível em: <http://www.snpn.com/ spip.php?article38>. Acesso em: 23 fev. 2015.

TYLOR, Edward B. Primitive culture. London: Murray, 1920, v. 1.

UNESCO. Convention concernant la protection du patrimoine culturel et naturel. Adoptée par la Conférence Générale à sa dix-septième session, Paris, 16 nov. 1972.

UNESCO. Recommandation concernant la sauvegarde de la beauté et du caractère des paysages et des sites. Actes de la Conférence Générale: résolutions $12^{\circledR}$ session, Paris, 1962, p. 141-146.

UNESCO. Recommandation concernant la sauvegarde des ensembles historiques ou traditionnels et leur rôle dans la vie contemporaine. Actes de la Conférence Générale: dix-neuvième session, annexe 1, Nairobi, p. 21-29, 25 out./30 nov. 1976.

UNESCO. Orientations pour l'inscription de types spécifiques de biens sur la Liste du Patrimoine Mondial. Paysages Culturels. In: UNESCO. Orientations devant guider la mise en oeuvre de la Convention du patrimoine mondial, annexe 3. 2, p. 89-98, 2008.

UNESCO. Orientações técnicas para a aplicação da Convenção do Patrimônio Mundial. Lisboa: UNESCO, 2012. Disponível em: <http://whc.unesco.org/archive/opguide11-pt. doc>. Acesso em: 25 abr. 2013.

UNESCO. Paysages culturels. Disponível em: <http://whc. unesco.org/fr/PaysagesCulturels/>. Acesso em: 5 fev. 2015.

UNESCO. World heritage. Cultural Landscapes. UNESCO-Icomos Documentation Centre. Disponível em: <http://whc. unesco.org/documents/publi_wh_papers_26_en.pdf>. Acesso em: 10 fev. 2009.

Recebido em 19/05/2015

Aprovado em 10/08/2015 